\title{
Trauer um Ernst Siegmund, der im April verstorben ist
}

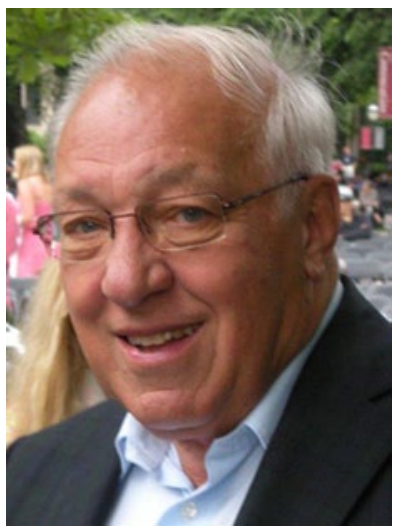

Am 23.April 2015 wurde Herr Vorstandsdirektor i. R. DI. Ernst Siegmund im 78. Lebensjahr völlig unerwartet aus unserer Mitte gerissen.

Wir erinnern uns an einen immer sehr aktiven vielseitigen Vorstand der voestalpine Schienen $\mathrm{GmbH}$. In der langen Zeit der Zusammenarbeit haben wir Ernst Siegmund nicht nur als ausgezeichneten Techniker und Manager, sondern auch als ganz besonders hilfreiche Persönlichkeit erlebt.

Ernst Siegmund wurde am 16. Feburuar 1938 in Hombuk geboren. Er schloss das BRG Bruck an der Mur mit der Matura ab und studierte an der Montanistischen Hoch- schule in Leoben, die er 1961 mit der 2. Staatsprüfung abschloss.

1961 trat er in die Felten und Guilleaume AG ein, wo er in der Versuchsanstalt des Werkes Diemlach Betriebsassistent und Betriebsleiter des Stahldrahtzuges, Patentierung und Glüherei in Bruck tätig war. 1970 übernahm er die Leitung der Werkes Bruck an der Mur, 1982 wurde er nach Übernahme des Werkes Bruck durch VOEST-ALPINE Austria Draht $\mathrm{GmbH}$ Mitglied der Geschäftsführung. Von 1992 bis 1995 war er Mitglied der Geschäftsführung BSTG Drahtwaren Produktions- und Handels $\mathrm{GmbH}$ in Linz.

Von 1993 bis zu seiner Pensionierung im Juli 2000 war er als Vorstandsmitglied der VOEST-ALPINE Draht GmbH fürTechnik, Produktion, Qualität und Personal verantwortlich. Ernst Siegmund wirkte erfolgreich in zahlreichen Aufsichtsratsfunktionen von VOEST-ALPINE Gesellschaften und Mitglied des Sparkassenrats der Sparkasse Bruck an der Mur - Kapfenberg.

Unsere besondere Anteilnahme gilt seiner Frau Eleonore, seiner Tochter Barbara und seinem Sohn Thomas und seinen Enkelkindern.

Wir alle werden Ernst Siegmund aufrichtig vermissen und ihm ein würdiges Andenken bewahren.

Ein stilles Glück auf!

Erich Meixner

Bruno Hribernik 